\title{
EMPIRICAL STUDY REGARDING THE INFLUENCE OF COMMUNICATION UPON THE PURCHASING DECISION
}

\author{
Dan POPESCU, Alina DINU, Cristina STATE, Cătălina PICU \\ The Bucharest University of Economic Studies, Romania \\ dan.popescu@man.ase.ro, alina.dinu92@gmail.com \\ cristina.state@man.ase.ro, catalina_picu@yahoo.com
}

\begin{abstract}
The aim of the present study is to emphasize the influence of communication upon the customer's purchasing decision. This objective is translated through determining the change of products in the sales' structure using communication by omission. The study is focused upon the purchasing selection between two similar products by the subjects included in the study. The difference between the two products lies in the customers' care for the environment. Thus, one of the two products does not pollute, in the conditions in which the application with care and attention is applied (this being expressed through a price difference compared to the other, polluting, product). The study has two phases in order to compare the sales structure in the situations in which it is used the communication through omission (in the second phase of the study) with the sales structure when the communication through omission is not used. The hypothesis according to which the purchasing process takes place according to the care for the environment and not necessarily according to the direct utility allocated to some apparently similar products has been tested through econometric instruments.
\end{abstract}

\section{Keywords: communication, decision, omission, sales}

\section{Introduction}

The decisions play an important role in the life of each person. Among the multitude of the decisions which a person adopts them in the daily life it is also the purchasing one. We decide what we purchase, why we purchase it, from where we purchase it, and, not lastly, the moment in which we purchase it. The purchasing behaviour consists in those „consumer's activities which imply the search for a better or of a service in order to satisfy the need or of a better item which he/she desires to purchase, the evaluation, gaining and its usage" [1]. Thus, our whole purchasing behaviour implies not only the decision-making process, but also the actions of the persons involved in the products' purchasing and usage. The decision-making process which a buyer adopts is influenced by three factors, namely: personal, psychological and social. The personal factors include, in their turn, the demographic factors (gender, age, income), the purchasing reasons (young individuals purchase products due to reasons different than the elderly ones) and the decisionmaking power within the family (the child from a family has a lower decision-making power in comparison to its other members). The psychological factors refer to the reasons, perceptions, attitudes, abilities and knowledge, personality and life-style of the buyers. The buyers' wishes and reasons are influenced by the opinion of the leaders, the persons within the family, the reference group, the social and culture class, while the 
purchasing decision can be adopted under the influence of an impulse or a detailed analysis of the product's features, as well as the context in which it is placed the purchasing decision [2]. The same authors sustain that there is an association of emotions such as, for example, the fantasy, sexuality, hope, fear, love, general joy for certain purchasing. Therefore, the purchasing impulse has a tight link with the emotions lived by the consumer at the time of purchasing. The purchasing decision can be influenced by the communication level through the adoption of a speech aimed at creating perceptions, attitudes (psychological factors) and emotions suitable for the purchasing of a product. Within the context of solving a particular issue with regard to the decision making, the features of the issue, of the person and of the social context are factors which influence the selection of the strategy appealed to in order to solve a particular issue for the decisionmaking relating to purchasing [3]. These strategies differ according to the number of alternatives taken into consideration. In the case of two or three alternatives, people sometimes select decision-making strategies which process the fully information relevant which exclusively requires a solution.

The purchasing process can be achieved in six stages, namely: the need to be acknowledge; the information search regarding the project; the evaluation of the project; the selection of the project; the purchasing, the usage and evaluation of the project; the disposal of the product [4]. The purchasing decision can be influenced through the obtaining of information during the second and third stage of this process. Our study is concentrated upon the intersection of two research fields: the decision-making process at the time of purchasing and the communication by omission. Thus, we will research the influence of communication by omission upon the purchasing decision. According to
Shuyan, ,the deceiving practices are often used in order to mislead the receiver of the message and can take the form of some facts, negations, omissions or exaggerations" [5]. Robert explains the difference between the lie and deception. In his opinion, ,... the lie is a message expressed by the user who intends to deceive the listener. The deceit is judged to be successful only when the listener perceives and interprets the message in contradiction with what the speaker believes." [6]. According to the same author, the essential condition for the deceitful or by omission communication's is that the listener believes that the speaker has no intention to deceit. The study of this theme in the speciality literature has passed from its research within a work negotiation session [6] to the investigation of the behaviour of the information providers and their users [7]. Paul, Wallance and Klaus [8] have revealed that ,the measurements for the hand and voice movements were changed significantly from the honest to the deceitful interaction". Knapp, Hart and Hary (1 determined which are the verbal and non-verbal characteristic components of this form of communication (the deceitful one), one of the studied behaviours being the smile. A recent study which was carried on by Shuyan has as research theme the detection of deceit with regard to the person's gender in the online communication. The study has shown that, in comparison to men, the women have the tendency to be (positively) motivated to deceit with regard to their gender. They also have more chances to recognise this type of deceit [9]. Another study analysis the way in which the behaviour of the deceit detecting systems' users is changed as an answer to the presence of the guilty knowledge. According to this study, there is a low percentage of innocent persons who have registered countermeasures [10]. Lina $Z$. [11] discovered that those who speak the truth, compared to those who deceive, are less present, dominant and cooperative. 
Dean [12] examined the relation between the duration of the answer, the time of the verbal answer and the deceit during an interview with an agent generated by the computer. The group analysis has shown that the duration of the answer is shortened in case of deceit. The aim of the present study is that of determining the influence of communication by omission on the purchasing decision. The study will answer the question: how does communication by omission change the sales structure?

\section{Methodology}

Our study was carried on 146 with age comprised between 19 and 72 years in the interval February - April 2017 in a shoe shop. After they have purchased the desire pair of shoes, the customers were suggested the purchasing of a maintenance product. In order to achieve the aim of this study, two similar products were selected. The two products, Nano-pro and Carbon-pro offer protection based upon the nano technology. The country of manufacturing, the composition, the types of material for which they can be used, the usage method, the manufacturing country and the quantity are identical characteristic for the two products. The difference between the two products lies in the care towards the environment which Carbon-pro has in the application of the product and an additional difference of 10 lei. The price difference between the products is explained by the innovative feature which Carbon-pro has (for the application of the product with the help of a system which is less polluting for the environment). The study was carried on in two phases. In the first phase, the customer was asked if he/she desires a shoe care product. The speech during the first stage contains a single, closed, question. To this question, it can be answered by yes or no. The customers who answered yes to this question were presented the two products and their different price, without other details. If the customers in the first phase of the study requested additional details and have purchased the product, they were included in the study. This speech was constructed in order not to influence the purchasing of a product in the detriment of the other. The second speech is a recommendation and the its aim is that of determining the customer to purchase the Carbon-pro.

Through this speech, the customers are presented the benefits of using a shoe care product and the two products. It is mentioned the similarity between the products and the cost of the products, and Carbon-pro is presented as an innovation in the field. The customers were placed in the situation of choosing between the two similar products. Carbon-pro is the product valued with 10 lei more than Nano-pro. Speech has omitted to present the customers the essential difference: Carbon-pro is more gentle with nature. In the situation in which the customer requested additional information regarding the differences (besides those presented in the speech) between the produces, 6this information has been offered, but that customer was not included in the study.

The data gathered contains information with regard to the education and age of the customers. In order to determine the change in the sales structure with the help of the communication by omission, the data in the first phase of the study were compared with those in the second phase of the study. In order to determine to what degree the age and not the communication influences the purchasing decision, we tested if there are significant differences between the average age and a certain education level for the customers who purchased Nano-pro and that of the customers who purchased Carbon-pro. The calculation of the indicators used in the testing were achieved with the help of the program Eviews 8. Ink. 


\section{Results}

During the first phase of the study, $82 \%$ of the customers purchased Nano-pro, while 18 $\%$ purchased Carbon-pro. In the second phase of the study, $55 \%$ purchased Carbonpro and $45 \%$ purchased Nano-pro. The stage in which the communication by omission was used was that in which it increased percentage of the customers who chose to purchase Carbon-pro (from 18\% to $55 \%)$ and has decreased the percentage of the customers who chose to purchase Nanopro (de la $82 \%$, la 45\%). The results associated with the speech used in the last phase were in favour of a product with a higher value. the customers with average education, from the initial study, past the 40 years of age, purchased $100 \%$ Nano-pro.

The customers with the average studies in the second phase of the study, past the age of 40 , purchased in proportion of $53 \%$ Carbon-pro and in proportion of $47 \%$ Nano-pro. The percentage of the customers with the average studies which have chosen to purchase Carbon-pro has increased from 0 $\%$, in the first part of the study, to $53 \%$ in the second part of the study. The results from the first phase of the study has shown that $96 \%$ of the customers with average studies, who are up to 40 years of age, have purchased Nano-pro and $4 \%$ have purchased Carbonpro. The customers with average studies who are up to 40 years of age have purchased Carbon-pro in proportion to $71 \%$ and Nano-pro in proportion to $29 \%$.
In the first phase of the study, $31 \%$ of the customers with higher education and up to 40 years of age have purchased Nano-pro and $69 \%$ have purchased Carbon-pro. The customers with higher education and up to 40 years of age have purchased in proportion de $60 \%$ Carbon-pro and Nano-pro in proportion de $40 \%$. In the first phase of the study, the Nano-pro product was purchased in proportion of $68 \%$ by the customers with higher education and in proportion of $32 \%$ by the customers with average studies. In the second phase of the study, the Nano-pro product was purchased in proportion of $58 \%$ by the customers with higher education and in proportion of $24 \%$ by the customers with average studies.

For the sample of 30 buyers of the Nano-pro product (from the second phase of the study), the average age is 39,57 years. Half of the purchasers of Nano-pro have the age under 38 years, and the others have an age past 38 years. The minimum value of the age for the 30 Nano-pro buyers is 19 , and the maximum value is 72 . The average age dispersion for the Carbon-pro buyers with average studies, measured using the average square deviation is 14,43 years. This shows that the age values of the Carbon-pro buyers with average education deviate with an average of (plus or minus) approximately 14 years from the average value. Asymmetry is positive to the right. The distribution is leptokurtic or sharp.

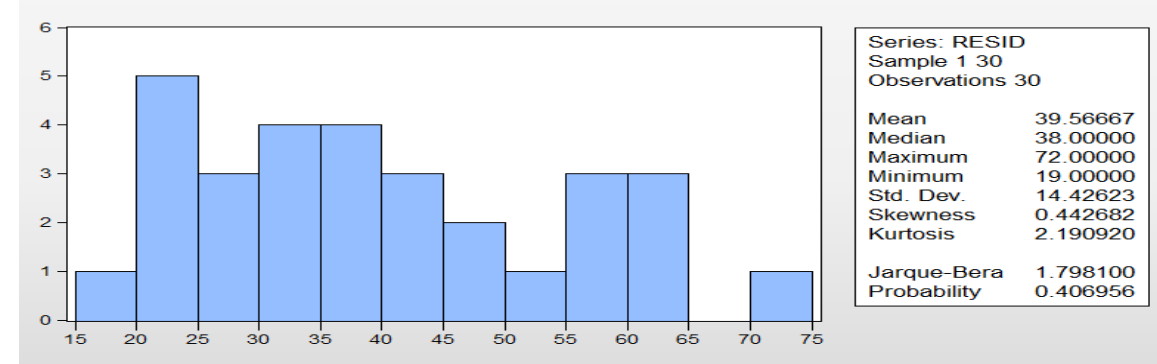

Figure 2: Indicators used in testing regarding the Nano-pro D2's customers age 
In Figure 2 it is observed that for the sample of 30 buyers of the product Carbon-pro, the average age is of 41,03 years. Half of the Carbon-pro buyers are younger than, and the others older than. The minimum age value for the 30 Nano-pro buyers is 26, and the maximum value is 63 . The average age dispersion for the Carbon-pro's buyers, measured through the average square deviation is 10, 63 years. This shows that the values of the Carbon-pro's buyers with average studies deviate, on average, with approximately (plus or minus) 10 from the average value. Asymmetry is positive to the right. The distribution is leptokurtic or sharp.

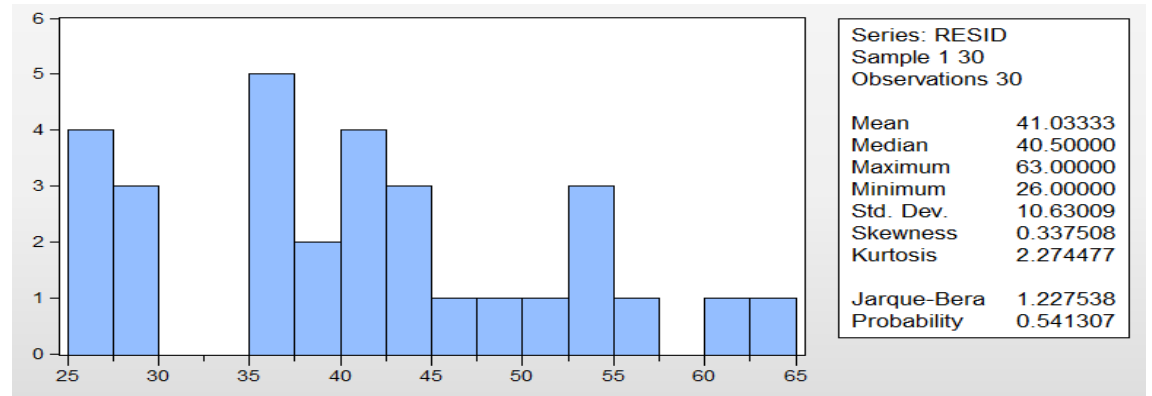

Figure 3: Indicators used in testing regarding the Carbon-pro D2's customers age

It is observed that for the sample of 13 buyers of the Carbon-pro product, the average age is 42,07. Half of the customers of Nano-pro are less than 42 years old and the others are older than 42. The minimum age value of the Nano-pro's buyers is 22 years and the maximum value is 61. The average age dispersion of the Carbon-pro's buyers with average studies, measured average square deviation is 11,16 years. This shows that the age value of the Carbon-pro's buyers deviates with an average of (plus or minus) approximately 11 years from the average value. Asymmetry is positive to the right. The distribution is leptokurtic or sharp. For the sample of 13 buyers (with average studies) of the Carbon-pro product, the average age is 40,61. Half of the Carbonpro's buyers with average studies are under 42 years of age, and the others are past 42 of years. The minimum age value of the 13 Carbon-pro's buyers with average studies is 26 and the maximum value is 62 . The average age dispersion of the Carbon-pro's buyers with average studies, measured average square deviation is 10,17 . This shows that the age value of the Carbon-pro's buyers deviates with an average of (plus or minus) approximately 10 years from the average value. Asymmetry is positive to the right. The distribution is leptokurtic or sharp.

In Figure 4 it is observed that for the sample of 13 buyers (with average study) of the Nano-pro product, the average age is 36,46 . Half of the Nano-pro's buyers with average studies have an age under 26, and the rest are past 26 years. The minimum age value of the 13 Nano-pro's buyers with average studies is 19 and the maximum value is 72 . 

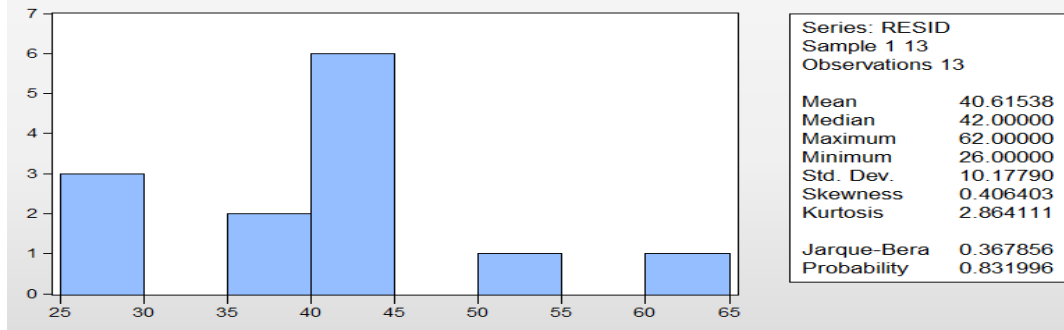

Figure 4: Indicators used in testing regarding the age of the Carbon-pro D2's customers with average studies

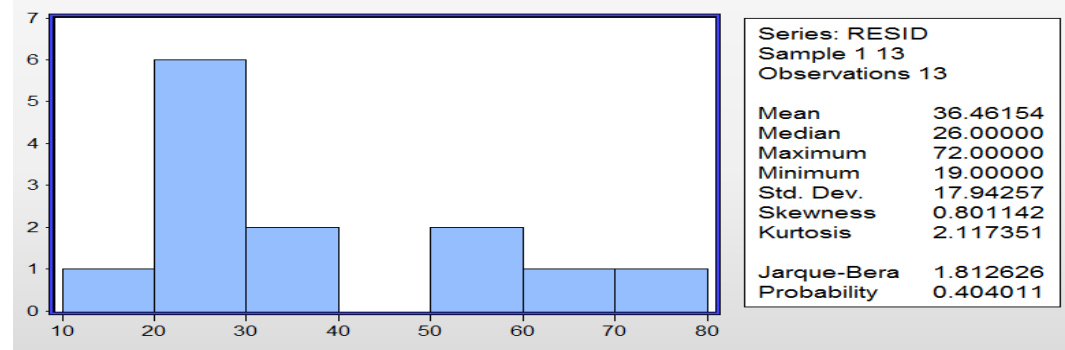

Figure 5: Indicators used in testing regarding the age of the Nano-pro D2's customers with average studies

The average age dispersion of the Nano-pro's buyers with average studies, measured average square deviation is 17.94 years. This shows that the age value of the Nano-pro's buyers deviates with an average of (plus or minus) approximately 18 years from the average value. Asymmetry is positive to the right. The distribution is leptokurtic or sharp.

4. Discussion In order to isolate the influence of the communication upon the purchasing decision, this study can be carried on in laboratory conditions. These conditions presuppose the minimization of the influence of the income level upon the purchasing decision. A way through which this can be achieved is offering a 69 lei value coupon to the subjects who participate in the study. Thus, the income level will not influence the selections to the same degree. Achieving similar studies for other almost identical products is another way. Creating a website in which to simulate the study carried on the marked will minimise the influence which the price and the seller have upon the customer's purchasing decision. The data collected contains information with regard to the customers' studies and age. This information can create an image of their income. For example, a 20-year old customer with average studies has a lower income level than a 45-years old customer with higher education. The validation of the results obtained on a sample comparative with the general characteristics of the population depends on the correctness of the application of the sampling techniques.

\section{Conclusions}

1. Structure differences are recorded in the sales during the second phase of the study. The stage in which the communication by omission was used was in which it increased (from $18 \%$ to $55 \%$ ) the percentage of the customers who chose to purchase Carbonpro and it decreased the percentage of the customers who chose to purchase Nano-pro (from $82 \%$ to $45 \%$ ). The results associated with the speech associated in the last phase were in favour of the product with the greater value. If in the first part of the study the customers with average studies, past the age 
of 40, purchased only Nano-pro, in the last part of the study, the share of customers purchased Carbon-pro was of $53 \%$. The percentage of the customers with average studies, with age up to 40 years, who purchased Carbon-pro increased from $4 \%$ in the first stage to $71 \%$ in the stage in which it was used the communication by omission. Following the first speech, $31 \%$ of the customers with higher education, up to 40 years of age, purchased Nano-pro and $69 \%$ purchased Carbon-pro. In the stage in which the communication by omission was used, the customers with upper education, of up to 40 years of age, who purchased in proportion of $40 \%$ Carbon-pro compared to the first phase of the study, when they had purchased in proportion of $69 \%$. The percentage of the customers with higher education who purchased Nano-pro has decreased from 68 $\%$ in the first stage of the study to $58 \%$ in the second phase of the study.

2. Communication by omission used in the last phase of the study balanced in proportion in which a certain product was purchased in the disadvantage of the other. If in the first stage of the study, Carbon-pro was in among the preferences of the purchasers' selection in proportion of $18 \%$, in the second phase of the study it increased to $45 \%$. Thus, it was achieved the objective of the second speech, that of determining the customers to purchase in a larger proportion Carbon-pro.

3. Within the sample of the second phase, there are no significant differences between the age averages of the customers with a certain level of studies who decided to purchase Carbon-pro and between the average of the customers who have the same level of studies and who decided to purchase Nanopro (the result is identical also upon testing the average of the customers who have a different education level). No significant differences were found between the age averages of the customers who purchased the same product, but have a different level of education.

\section{References}

[1] Khaled, I., A-R., A-J. (2008) Consumer Behavior. An analytical Study of The Saudi Family's Purchase Decisions. Available at: https://d1.islamhouse.com/data/en/ih books/single/ en Consumer Behavior.pdf, (accessed on March, 17 $7^{\text {th }}, 2017$ )

[2] Schiffman, L., Kanuk, L. (2007) Consumer Behavior, $9^{\text {th }}$ Edition. New Jeresy: Pearson.

[3] Payne, W., J., Bettman, J. R., Johnson, E. J. (1993). The adaptive decision maker. Cambridge: Cambridge University Press.

[4] Tanner, J.-F., Jr., Raymond, M.-A. (2010). Principles of Marketing, New York, Flat World Knowledge, Inc.

[5] Shuyuan, M. H., Paul B. L., Merrill W., Yanyun Y., Jonathan M. H. (2017). "Gender deception in asynchronous online communication: A path analysis", Information Processing \& Management, 53/(1), January, 2017, pp. 21-41.

[6] Robert, E. T. (1984). The definition and function of deceptive communication in a labormanagement session, Doctoral Thesis, Arizona: The University of Arizona.

[7] Roman, M. S., Timothy, W. S. (2017). "Deception and reception: The behavior of information providers and users", Journal of Economic Behavior \& Organization, Vol.137, May 2017, pp.445-45. Available at: http://www.sciencedirect.com/science/article/pii/S0167 268117300823 , (accessed on April, 25 $\left.{ }^{\text {th }}, 2017\right)$

[8] Paul, E., Wallace, V. F., Klaus, R. S. (1976). "Body movement and voice pitch in deceptive interaction", Semiotica 16/(1), pp.23-27. Available at: https:/www.paulekman.com/wpcontent/ uploads/2013/07/Body-Movement-And-Violence-Pitch-In-DeceptiveInteraction.pdf (accessed on April, 20 ${ }^{\text {th }}, 2017$ ). 
[9] Shuyuan, M. H., Paul B. L., Merrill W., Yanyun Y., Jonathan M. H. (2017). "Gender deception in asynchronous online communication: A path analysis", Information Processing \& Management, 53/(1), January, 2017, pp. 21-41.

[10] Jeffrey, G., Randall, B., Ryan, M. S. (2016). "Man vs. machine: Investigating the effect of adversarial system use on end-user behavior in automated deception interviews", Decision Support Systems, Vol. 85, May 2016, pp.23-33. Available at: http://www.sciencedirect.com/ science/article/pii/S0167923616300197, (accessed on April, 13 $\left.{ }^{\text {th }}, 2017\right)$.

[11] Lina, Z., Jiang, W., Dongsong, Z. (2014). "Discourse cues to deception in the case of multiple receivers", Information \& Management, 51/(6), pp.726-737. Available at: http://www. sciencedirect.com/science/article/pii/S0378720614000640, (accessed on February, 27 $7^{\text {th }}$, 2017).

[12] Dean, A., Robert, J. W., David, C. S. , Grant, T. L. , Cynthia, C., John, W. R. (2017). "Verbal response time and duration indices of deception in humans interviewed by a computer-generated agent”, Int. J. Human-Computer Studies, Vol. 27, pp. 23-33. 